\title{
Work and activity in rehabilitation of persons with co-occurring severe mental health difficulties and substance use problems
}

\author{
Sissel Steihaug ${ }^{1,2 \#}$, Anne Werner $^{2}$, Tonje Lossius Husum ${ }^{1}$ \\ ${ }^{1}$ SINTEF, Oslo, Norway; ${ }^{\#}$ Corresponding Author: sissel.steihaug@sintef.no, tonje.l.husum@sintef.no \\ ${ }^{2}$ Health Services Research Centre, Akershus University Hospital, Lørenskog, Norway; anne.werner@ahus.no
}

Received 11 April 2013; revised 12 May 2013; accepted 10 June 2013

Copyright (C) 2013 Sissel Steihaug et al. This is an open access article distributed under the Creative Commons Attribution License, which permits unrestricted use, distribution, and reproduction in any medium, provided the original work is properly cited.

\section{ABSTRACT}

Background: Participating in working life is important for most peoples' economy, self-confidence, independence, social life, and feeling of belonging. Persons with co-occurring severe mental health difficulties and substance use problems have challenges in entering working life. Objective: The aim of the study was to explore the importance of work and activity for the recovery of persons with co-occurring severe mental health difficulties and substance use problems and to determine the significant elements that aid them in getting into work and/or meaningful activities. Methods: A professional development program was conducted to explore how following-up on these persons could lead to participation in working life. The data were collected through qualitative interviews with 24 participants, and with 25 of those carrying out the follow-up. Results: The participants described the benefit from the follow-up as well. They expressed enthusiasm for work and vocational training, although they all did not obtain work. Many had a better life, with more daily structure and less substance abuse. The personal encounter between the helper and the participant was ascribed crucial importancebeing respected and valued, being relied on, and being able to be honest were considered significant. Conclusions: The participants valued work and regular activities, a more structured life, decreased drug abuse, and altogether a better life. The helpers' respect, recognition and their ability to see dignity through wretchedness

"Declaration of Conflicting Interests: The authors declare that there is no conflict of interest. and broken agreements were important. The participants emphasized the importance of getting help for different problems from different helpers at the same time, and the providers' interdisciplinary collaboration in teams was essential. It seems that the supported employment philosophy on speedy job seeking ought to be adapted to this target group and that prior social training may be necessary.

Keywords: Rehabilitation; Work; Co-Occurring Mental Health Illness and Substance Abuse; Collaboration; Qualitative Research

\section{INTRODUCTION}

\subsection{Background}

To participate in working life is important for most people. Work has consequences for a person's economy, self-confidence, independence, social life, and the feeling of belonging.

Severe mental illness can lead to functional difficulties and thereby difficulties in working life. In spite of the fact that many people with severe mental health difficulties want to work, their participation in working life is low $[1,2]$. Studies in UK show that while $45.6 \%$ of the whole group "disabled people" are in employment, only $14.2 \%$ of people with mental illness are employed [3]. It appears that for those suffering from mental health difficulties, having an ordinary job is associated with financial stability, improvement of symptoms, greater selfconfidence and a better quality of life [1,4,5].

Persons with abuse problems find themselves outside the ordinary working life [6,7]. At the same time, work can improve symptoms and provide the motivation to stop substance abuse and can be instrumental in control- 
ling it [6].

Many persons who suffer from mental illness also have substance abuse problems, and many of those with substance abuse problems suffer from severe mental health difficulties $[8,9]$. The services offered to persons with dual diagnosis have mostly been inadequate, partly due to negative and stereotype attitudes to substance abuse $[10,11]$. Co-occurring mental health difficulties and substance abuse can make it more difficult to enter working life, and it seems to be the mental problems that are the greatest barriers $[12,13]$. Persons suffering from co-occurring difficulties often need considerable adaptation and follow-up if they shall succeed in getting and keeping a job. It is well documented that integrated treatment for the mental health difficulties and the substance abuse is important, that the help must be individualized, and that these persons often need help in different domains, such as housing, economy, etc. [14-16]. More knowledge is needed about what is optimal help for this group in obtaining work [8]. This study explores the participants' experiences with a follow-up program for people with co-occurring mental difficulties and substance abuse when the aim is to help them to obtain work.

\subsection{Context of the Study}

As part of the National Strategic Plan for Work and Mental Health 2007-2012 [17], the Norwegian Labour and Welfare Service (NAV) in Norway conducted a professional development programme, an initiative to show how mastering mental health difficulties and substance abuse problems could lead to participation in working life (Mestringsveier til arbeid-psykisk helse og rus) from autumn 2009 till December 2011. The aim was to develop an appropriate follow-up method for assisting individuals with co-occurring severe mental illness and substance abuse problems to find jobs. As researchers, we have studied the programme development in three counties in Norway (hereafter referred to as County I, County II and County III).

The participants received follow-up from experts with competence in the fields of mental health, substance abuse initiatives, and vocational rehabilitation. At the point of departure, there was no formalized collaboration between the providers, but during the period of the project, the providers organized into teams with regular meetings from every second to every fourth week. In two of the counties the providers succeeded in developing a god interdisciplinary collaboration in the team. The providers told us about considerable disagreements and conflict in the beginning, but through discussions and negotiations, they managed to work out a mutual understanding of each other's tasks and roles and a common attitude and approach towards the participants.

\section{AIM}

The aim of the study was to explore the importance of work and activity for the recovery of persons with cooccurring severe mental health difficulties and substance use problems and to determine the significant elements that aid them in getting into work and/or meaningful activities.

\section{MATERIAL AND METHODS}

This article emphasizes the user perspective and examines the participants' experience of the follow-up, and we decided to gather data through qualitative interviews with the participants (24 persons). In addition, some supplementary information was collected from those carrying out the follow-up (25 persons).

\subsection{Individual Interviews}

The participants and those conducting the follow-upwere interviewed twice each year in 2010 and 2011 when the researchers visited the three projects. The interviews were semi-structured and based on interview guides prepared in advance [18]. The participants were asked about their experience of taking part in the project. The interviews focused on elements that were of significance for them getting into work and/or meaningful activities and the importance of being in work and/or meaningful activities.Those conducting the follow-up were asked about their appraisal of the participants' benefits of the project. The interviews were conducted face to face, lasted from 30 minutes to one hour, were recorded on digital recording equipment and were transcribed verbatim.

\subsection{Participant Informants}

A total of 55 persons took part in the three projects, 24 of whom were interviewed. See Table 1.

All the participants in County II were interviewed. Informants in Counties I and III were recruited by those conducting the follow-up on the basis of who was able to attend the interview on the day in question. In County I it was often difficult to get hold of informants-some of them forgot to come, and some were institutionalized on the day in question. Most of those in County III reported for the interviews. Each participant was interviewed from one to four times. Participants who were at work and on educational programmes are under-represented in the material since they gave priority to their job/education rather than to the interview. Three participants who withdrew from the projects were interviewed.

\subsection{Data Analysis}

Our qualitative data comprise interview transcripts. The data have been analyzed using a four-step analysis 
Table 1. Participants in the different counties.

\begin{tabular}{|c|c|c|c|c|c|c|c|}
\hline County & $\begin{array}{l}\text { Participants } \\
\text { interviewed }\end{array}$ & $\begin{array}{c}\text { Women } \\
\text { interviewed }\end{array}$ & $\begin{array}{c}\text { Men } \\
\text { interviewed }\end{array}$ & $\begin{array}{l}\text { Participants' } \\
\text { age in years }\end{array}$ & $\begin{array}{l}\text { Average age in } \\
\text { years }\end{array}$ & $\begin{array}{l}\text { Total no. of } \\
\text { interviews }\end{array}$ & $\begin{array}{l}\text { Total no. of } \\
\text { participants }\end{array}$ \\
\hline County I & 8 & 2 & 6 & $23-35$ & 31 & 14 & 18 \\
\hline County II & 6 & 2 & 4 & $22-38$ & 27 & 17 & 6 \\
\hline County III & 10 & 3 & 7 & $24-45$ & 35 & 17 & Approx. $30^{*}$ \\
\hline Total & 24 & 7 & 17 & & & 48 & Approx. $55^{*}$ \\
\hline
\end{tabular}

*No exact figures are available due to changes in staff in County III.

method of systematic text condensation suitable for analysing the material transversely and condensing information from various individuals [19]. In the first step we read all the material to obtain an overall impression focusing on what is described as useful help for obtaining employment and/or meaningful activities and the significance of being in work in the informants' narratives. While re-reading the material we noted preliminary topics we were able to identify in the text. The second analytic step included the coding process based on these preliminary topics, where we identified and classified meaning units relevant to the aim of this study. The meaning units were developed, refined and systematised into codes, and the codes were then assembled into code groups under appropriate headings. In the third step we analysed and condensed the contents of each code group. The fourth step comprised summarising the condensed text in all the code groups into a précis, i.e. an analytical text that constitutes our results. Quotations from the interviews were selected to illustrate our points. In practice the analysis is not a linear process as described here, but alternates between the various steps throughout the entire procedure.

\subsection{The Participants in the Three Projects}

The inclusion criteria to the programme were severe mental illness, drug abuse, and wish for a job. The local projects recruited the participants, and there was some dissimilarity between the participants in the three counties.

In County I all the participants suffered from serious functional difficulties. Six participants never started in the project or stopped after a short time, and one died. Seven of the eleven participants who completed the project were institutionalized or imprisoned at the end of the project. The participants said that they started using intoxicants in their early teens, and several described a problematic childhood and adolescence with deficient care. Many had had several long-term periods in institutions for substance abusers and/or in inpatient units in the mental health care service. They told us about psychiatric diagnoses such as psychosis, borderline personality disorder, depression and social phobias, and many said they had been diagnosed with ADHD. Several mentioned dyslexia. Almost all of them had had inadequate schooling and limited or short-term work experience, while some had not been in work at all.

In County II the project participants were resident in five transitional dwellings that they had moved to from an inpatient psychiatric unit. Except for one they did not have serious substance abuse problems. Some of them had had several stays in inpatient units in the mental health service or previously in child welfare institutions. None of them mentioned psychotic illness but described anxiety, depression and social phobias as well as various neurological/cognitive difficulties. Two of them had some work experience, but the majority had never participated in working life.

In County III some participants left during the project period because they obtained work or started an educational programme (no exact figures are available), and some of them left without having got a job. New participants were continuously enrolled. At the end of the project there were 15 participants. The participants in this county had a clearer attitude to intoxicants than those in County I, and they wanted work, but there was no requirement regarding them being "clean". They told us about considerable previous substance abuse, but with a somewhat later debut than the participants in County I. Most of the participants had had several periods in institutions for substance abusers but more seldom in inpatient units in the mental health service. They described mental health difficulties, but these were less serious than those in County I. Most of them had had more schooling and far more work experience than the participants in County I.

\section{RESULTS}

First in the result section, the providers' view of the participants' benefit from the study is described. The participants' experiences dealt with different themes and can be summarized under the headings: "The helpers offer support and treat us with respect”; "A more structured life and less substance abuse"; "Great to be in employment—but challenging to be in the work situation"; "Financial problems". 


\subsection{Participants' Benefit from the Mastery Project as Evaluated by the Helpers}

Of the 18 participants in County I, eight had been in work practice and two in paid employment during the project period, with the employment lasting from two weeks to six months. Some of them never actually started the project. The four participants who were not in an institution at the end of the project were in a stable situation and were managing their lives reasonably well. By the end of the project, all the participants had established a contact person for treatment, and the project employees were of the view that all 11 of them were progressing well towards a better life with more stability and less substance abuse.

In County II, two of the six participants were in ordinary work and two in adapted work positions, while the remaining two were not in work by the end of the project. The helpers appraised the following up as useful for most of the participants in County II, even the two who were not in work. They had got their situation clarified for further support after the end of the project.

Of the 15 who by the end of the project formed part of the project in County III, two were in ordinary apprentice positions, one was in ordinary employment with followup, one had work practice and one was to start work shortly. Of the remaining ten, three were being assessed for work capacity, five were being followed up while they waited for treatment/other options, and two participated in internal activities and had no plans for obtaining work. Those responsible for follow-up believed many of the 15 participants might obtain ordinary work in the longer term presupposed further support.

\subsection{The Helpers Offer Support and Treat Us with Respect}

In all the counties the participants emphasized that their contact with the helpers was crucial. They described in various ways the experience of being recognized, respected and valued, and of feeling secure. Several stressed how important it is to be able to be honest. Trust was also a word that was often used. One person said it was very positive not to be nagged but simply encouraged. Another put it as follows:

"I have a good collaboration with the person who's following me up. I really trust this person! Even though I feel I sometimes make a fool of myself, I'm not corrected. It's very important to feel secure and to be completely honest. Things are less stressful when you don't have to hide anything. It's possible to admit that you can't manage to be completely clean all the time, and the project workers accept that".

Most of the participants emphasized that it is important to have a regular contact person over a period of time-a person they learn to rely on. Several described how the helpers support them when they need it because they understand that they are struggling and how they are helped to get their daily lives in order.

\subsection{A More Structured Life and Less Substance Abuse}

All the participants who were interviewed said that the mastery project had been important for them, and that they had benefited from participating. Many of them said they had got their lives better organized and that they therefore used intoxicants less. They talked about having something to go to regularly in their daily life and having their finances in order, and said they had established contact with other parts of the support system. Many informants in Counties I and III said that the project activities were the only thing they had to fill their days with and emphasized that without these activities they would have used intoxicants more:

"If I hadn't taken part in the project I would either be in my grave or heavily into intoxicants".

"I've been given support and help to join activities. Without the mastery project I wouldn't have had any structure in my life. It's important to have something to do during the day. It's really risky for me to sit there on my own-I need to have people around me. Without this service I could easily have started with drugs and alcohol again".

Several participants emphasized that two or three regular activities a week could be enough to create structure in their lives and keep them away from substance abuse. Many told us that they had difficulties with social life and stressed how good it was to be able to spend time with those who were doing the follow-up and with other participants - to eat lunch with them and to work together on various activities. One pointed out that as long-term substance abusers they have to re-learn how to live, and that the social contact in the project is therefore important. Many of them said they had had specific benefit from being together-like learning how to get up in the morning, arriving on time, being honest, structuring daily life, spending time with others and letting people know if they were unable to come. One participant described it as follows:

"I've learnt to be punctual, eat breakfast and disagree politely. I've learnt to rely on people, and about the difference between yours and mine".

Many underlined the fact that the various help initiatives were coordinated-for example that the vocational training service was part of a larger context and that the vocational rehabilitation specialists collaborated with those giving the treatment. Several said they had different problems regarding working, and that the various helpers could contribute different types of assistance. 
One told us:

"I've been so pleased with the help here-the regular follow-up about finances, leisure time, work, education and telephone calls. All-round help! More areas of assistance than in the substance abuse follow-up service. But I think the time is too short for many participants. It takes a long time to get out of a life of substance abuse".

\subsection{Great to Be in Employment-But Challenging to $\mathrm{Be}$ in the Work Situation}

In Counties II and III the participants started to work in an internal work-mapping setting. Most of them thought it was positive to start with internal activities before they began applying for "proper" jobs. Many said they needed to practice in safe surroundings before entering working life, and pointed out that it was particularly important to learn to adapt to the work situation. One participant put it this way:

"There's nothing physically wrong with my work capacity, so coping with work isn't so very problematic. The challenge is to manage being in a work situation".

However, in both counties many participants felt that there were too few activity options, that the tasks were boring and that there was too little "proper" work in these settings. Many of them wanted more "real" external work opportunities. One of them said:

"If you're going to get used to working life today, you have to go out and get a job anyway. It isn't something you learn at such a sheltered workplace. They've done what they can here, but I'd rather have help to get an external job. I think that's the best help they can give".

Some of them expressed clearly that the internal activity phase can be necessary, but that it took too long for the project employees to "push" the participants to try external work. Participants in all the counties who had been in work described the experience as good: acquiring work experience, having something to go to regularly, feeling useful and experiencing being "normal". Participants who had achieved ordinary employment told us about improved self-confidence and a better life.

Even though the participants who had been out in external work practice were usually enthusiastic, several said that it could be tiring, that they had been absent frequently, or that they had had to cut down or leave because it became too demanding. Several of them described the ambivalence between the internal security and the insecurity of an external job.

\subsection{Financial Problems}

In all the projects the participants were concerned about their personal economy-principally because they had to have something to live on. Almost all of them were receiving work assessment allowance from the La- bour and Welfare Service (NAV), and most of them had been given help in the project to apply for this. For many of them this meant a financial security they had not experienced before. The debt problem preoccupied many of those who struggled with substance abuse and several of them were of the view that worry about debt is a main cause of relapses and giving in to substance abuse again. However, one participant pointed out that he/she had had considerable help from a course that was run in the project:

"I got help to see things in an overall perspective, to stop sticking my head in the sand. I've learnt to think: just how much have you got, what date is payment due etc. I've reached a 'knowledge level'. I've been most concerned about the money I had there and then-it's easy to forget the rest!"

\section{DISCUSSION}

The participants who were interviewed described the benefit from the follow-up as good. Many of them expressed enthusiasm for work/workpractice/education, and many told us of useful internal vocational training. Many participants described how helpful the training in social skills had been, and many told us they had a better life with more daily structure and less substance abuse. Even in County I-where none of the participants managed to get out into working life-it appears that most of them were progressing towards a better life. Important elements in the follow-up were described and these will be discussed below.

\subsection{Important Contact between User and Helper}

In accordance with the abundant literature, the results in this study also show that the personal encounter between the helper and the person who is to be helped is ascribed with crucial importance-being respected and valued, being relied on, and being able to be honest.

The authors of a recent knowledge summary present the therapeutic alliance as essential to and a prerequisite for the treatment of this patient group [15]. The cooperation between the provider and the patient forms the basis for the change processes. When treating substance abuse problems, there is a direct correlation between the patient/therapist relationship and the result of the treatment [15]. A considerable number of these patients have experienced many serious breakdowns in relationships previously, and the relevant literature documents a high incidence of maltreatment, assault and failure of care in childhood [20-22]. It will therefore be demanding to build trust, and this is conditional on respect for and recognition of the individual who is to be helped. It is challenging to communicate an attitude of recognition, and 
the greater the difference between the therapist and the patient the more challenging the situation becomes. The psychologist Anne-Lise Løvlie Schibbye describes reconition as fundamental respect for the experience perspective of the other party, and argues for the fact that the helper's respect can create change in the user [23]. She describes how an attitude of recognition can be expressed in interaction as listening, understanding, acceptance, tolerance and confirmation. These expressions correspond well with the participants' narratives about what was important for them in the mastery projects. In our view, Schibbye's descriptions of approaches involving recognition can be of considerable help in practical clinical work.

\subsection{An Integrated Perspective}

The participants underlined that they were given help for various difficulties, at the same time as they stressed how important it was that the helpers collaborated. Treatment of mental health difficulties and substance abuse problems ought to be integrated [14,15] and this implies good collaboration between the providers. Collaboration is emphasized when experienced clinicians summaries their experience of vocational rehabilitation for persons with co-occurring severe mental illness and substance abuse problems [12]. The clinicians point out that the rehabilitation and the treatment of the mental illness and the substance abuse problems must be integrated and that the collaboration should be organized as a team. Integration is described as the vocational specialist understanding the substance abuse and the phases in the recovery process of the individual concerned, and the treatment specialist supporting the recovery process and recognizing the importance of work. The participants in this study value the providers' collaboration. The providers told us that they needed to organise the collaboration in teams to be able to follow up the participants in an adequate way in practice. Becker et al. point out that knowledge of substance abuse must be included in the team's mindset when they are to help a user to obtain work, and that the helpers must know at what stage the job applicant is in his or her recovery process from the abuse, what his/her substance abuse profile is like, what triggers the abuse etc. [12]. Brousselle et al. underline that what they call "normative integration" is a major challenge for providers; i.e. to develop common ways of addressing co-occurring disorders [24]. Traditionally, the psychiatric and the rehabilitation sectors have had different philosophies of practice that clearly dictated how the professionals responded to the patients' needs. Through repeated discussions and negotiations in the group, the providers in two of the counties in this study succeeded in establishing good interdisciplinary collaboration in the team, and probably a normative integration of their approach to the participants. In the third county they did not have the same conditions for collaboration and did not reach the same extent of collaboration

Becker et al. emphasize that the team must keep in contact with the users in the event of them relapsing. It is stressed that relapses are the rule rather than the exception for substance abusers, and that a plan must be agreed to prevent this. The participants in the mastery project study talked at length about relapsing and about the importance of meaningful activities, regular appointments and structure in daily life to prevent it. They emphasized that relapses must be allowed in the rehabilitation process, and that the users must feel that they dare to tell the helpers about them.

\subsection{The Importance of Work and Activity}

The participants conveyed enthusiasm about obtaining external work, even though several of them said that it had been demanding and some had had to leave their jobs. Many had been uneasy about trying to begin working, and said that the support and encouragement from those who followed up had been decisive. Kelly et al. point out that users with co-occurring mental illness and substance abuse problems may have been without work for some time, and one main point is to give them hope [15]. The participants in this study described in various ways how they experienced that the helpers conveyed hope and a belief in them in spite of their relapses and defeats. It is clear that this was significant for them, and it can indicate that such experience was new for many of the participants.

The benefit of supported employment (SE) as a method for vocational rehabilitation seems to be useful for persons with severe mental illness [25,26]. The method emphasizes speedy job seeking with a view to further work surveys being conducted after the individual has started in work [1], on an individual approach, and on long-term support [27]. SE is to a lesser extent investigated for those suffering from substance abuse problems in addition, but seems to be helpful for them as well [12,28-30]. The participants in this study said that it took too long for the project employees to "push" them to try external work, and those who had been in work were usually enthusiastic. Several had, however, had to cut down or leave because it became too demanding. This shows that it is important to find the correct time to begin working. The informants talked at length about the benefit of learning social skills before they starting working, and many of them pointed out that they were not ready to enter employment when they began the mastery project. The internal vocational training was described as practicing being at work rather than performing the work itself. The results indicate that some of those who have cooccurring severe mental health difficulties and substance 
abuse problems may need extra time before starting in ordinary jobs.

The participants who had achieved ordinary employment were very satisfied and having a job seemed to be important for their economy, social life and self-confidence. Relatively few participants achieved ordinary employment. However, many succeeded in carrying out regular activities and described how important this was for them. This can be the first step towards work. This study cannot report how many of the participants may have entered working life in the long term. However, many pointed out that there was not enough time, which may indicate that significant changes could have taken place in the longer run. Experience shows that long-term follow-up may be necessary [4].

\subsection{Methodological Considerations}

The interviews were an appropriate way of acquiring knowledge of the participants' experience and of their reflections on this. It was an advantage that many participants were interviewed several times so that more details could be obtained about their experience and their changing process. In Counties I and III informants were recruited pragmatically on the basis of who had the opportunity to attend, while in County II they were all interviewed. The fact that it was difficult to recruit informants in County I and that participants in work/educational programmes were under-represented may mean that we have not included participants with the most problems or those who to the greatest extent succeeded in getting into work. However, the descriptions of the participants' experience were varied, and the project employees were of the opinion that there was little difference between the participants who were interviewed and those who were not with regard to the extent of their problems and their benefit from and experience of the project.

\section{IMPLICATIONS FOR PRACTICE}

The contact between user and helper is crucial for helping those with co-occurring severe mental illness and substance use problems to find jobs. Establishing a good relationship with the user is to a large extent dependent on the helper's sense of security, and on his or her personal suitability and relationship skills. The individual employment specialist's competencies seem to influence rates of competitive employment [29,31]. These behavioral skills can to a certain extent be learned and developed, and in our view it must therefore be given attention and emphasis in practice, i.e. the person responsible for the follow-up must have sufficient time for contact with the user and must be given guidance as well as time and space for reflection. Attitudes are important for good professional work for this group, and the work involves respect, recognition and the ability to see dignity through wretchedness and broken agreements. We argue that Schibbye's perspective of recognition can be of specific assistance in clinical practice. Her description of how an attitude of recognition can be expressed as listening, understanding, acceptance, tolerance and confirmation can guide the helper and enable him or her to see dignity through wretchedness and broken agreements.

The participants appreciate and benefit from the training in social skills before they are to enter working life, and many of them say that they were not ready to start work. It may be that the SE philosophy on speedy job seeking must be adapted to this target group and that prior social training may be necessary for some people who have had long-term substance abuse problems in addition to their mental health difficulties.

\subsection{Ethical Considerations}

The application was submitted to the Regional Committee for Medical and Health Research. The project was not found to be part of the Committee's mandate since it is not regarded as medical or healthcare research conducted with the purpose of generating knowledge about illness or health (ref. 2010/817-1). The project was approved by the Norwegian Social Science Data Services (ref. 24238). Written, informed consent was obtained from the participants.

\subsection{Funding}

The conducting and evaluation of the initiative to show how mastering mental health difficulties and substance abuse problems could lead to participation in working life-the project "Mestringsveier til arbeidpsykisk helse og rus"-was funded by the Directorate of Labour and Welfare Service (NAV). SINTEF and Akershus University Hospital financed the writing of this article.

\section{THE AUTHORS' CONTRIBUTION}

Sissel Steihaug, Senior Researcher, MD, Ph.D., has designed the study, has had the primary responsibility for conducting the research project, the data analyses, and the article writing.

Anne Werner, Senior Researcher, sociologist, Ph.D., has contributed to the article writing.

Tonje Lossius Husum, Psychologist, Ph.D., has contributed to conducting the study, carried through the interviews with some of the participants and contributed to the article writing.

\section{REFERENCES}

[1] Crowther, R.E., Marshall, M., Bond, G.R. and Huxley, P. 
(2001) Helping people with severe mental illness to obtain wok: Systematic review. Bulletin Medical Journal, 322, 204-208. doi:10.1136/bmj.322.7280.204

[2] Rinaldi, M. and Perkins, R. (2007) Comparing employment outcomes for two vocational services: Individual placement and support and non-integrated pre-vocational services in the UK. Journal of Vocational Rehabilitation, 27, 21-27.

[3] Beyer, S. (2012) The progress towards integrated employment in the UK. Journal of Vocational Rehabilitation, 37, 185-194.

[4] Becker, D., Whitley, R., Bailey, E.L. and Drake, R.E. (2007) Long-term employment trajectories among participants with severe mental illness in supported employment. Psychiatric Services, 58, 922-928. doi:10.1176/appi.ps.58.7.922

[5] Koletsi, M., Niersman, A., van Busschbach, J.T., Catty, J., Becker, T., Burns, T., Fioritti, A., Kalkan, R., Lauber, R., Rössler, W., Tomov, T. and Wiersma, D. (2009) Working with mental health problems: clients' experiences of IPS, vocational rehabilitation and employment. Social Psychiatry and Psychiatric Epidemiology, 44, 961-970. doi:10.1007/s00127-009-0017-5

[6] Henkel, D. (2011) Unemployment and substance use: A review of the literature (1990-2010) Current Drug Abuse Reviews, 4, 4-27. doi:10.2174/1874473711104010004

[7] Laudet, A.B. (2012) Rate and predictors of employment among formerly polysubstance dependent urban individuals in recovery. Journal of Addictive Diseases, 31, 288-302. doi:10.1080/10550887.2012.694604

[8] Sacks, S., Chandler, R. and Gonzales, J. (2008) Responding to the challenge of co-occurring disorders: Suggestions for future research. Journal of Substance Abuse Treatment, 34, 139-146. doi:10.1016/j.jsat.2007.03.008

[9] Swendsen, J., Conway, K.P., Degenhardt, L., Glantz, M., Jin, R., Merikangas, K.R., Sampson, N. and Kessler, R.C. (2010) Mental disorders as risk factors for substance use, abuse and dependence: Results from the 10-years followup national comorbidity survey. Addiction, 105, 11171128. doi:10.1111/j.1360-0443.2010.02902.x

[10] Todd, F.C., Sellmann, J.D. and Robertson, P.J. (2002) Barriers to optimal care for patients with coexisting substance use and mental health disorders. Australian and New Zealand Journal of Psychiatry, 36, 792-799. doi:10.1046/j.1440-1614.2002.01049.x

[11] Adams, M.W. (2008) Comorbidity of mental health and substance misuse problems: A review of workers' reported attitudes and perceptions. Journal of Psychiatric and Mental Health Nursings, 15, 101-108. doi:10.1111/j.1365-2850.2007.01210.x

[12] Becker, D.R., Drake, R.E. and Naughton W.J., Jr. (2005) Supported employment for people with co-occurring disorders. Psychiatric Rehabilitation Journal, 28, 332-328. doi:10.2975/28.2005.332.338

[13] Laudet, A.B., Magura, S., Vogel, H.S. and Knight, E.L. (2002) Interest in and obstacles to pursuing work among unemployed dually diagnosed individuals. Substance Use \& Misuse, 37, 145-170. doi:10.1081/JA-120001975
[14] Judd, P.H., Thomas, N., Schwartz, T., Outcalt, A. and Hough, R. (2003) A dual diagnosis demonstration project: Treatment outcomes and cost analysis. Journal of Psychoactive Drugs, 35, 181-192.

[15] Kelly, T.M., Daley, D.C. and Douaihy, A.B. (2012) Treatment of substance abusing patients with comorbid psychiatric disorders. Behavioral Addiction, 37, 11-24. doi:10.1016/j.addbeh.2011.09.010

[16] Carpenter-Song, E., Hipolito, M.M. and Whitley, R. (2012) "Right here is an oasis": How "recovery communities" contribute to recovery for people with serious mental illnesses. Psychiatric Rehabilitation Journal, 35, 435-440. doi: $10.1037 / \mathrm{h} 0094576$

[17] NAV (2006) National strategy plan for work and mental health 2007-2012. In English.

http://www.nav.no/Arbeid/Jobb+og+helse/Aktuelle+tema /187410.cms

[18] Kvale, S. and Brinkman, S. (2009) Interviews: Learning the craft of qualitative research interviewing. 2nd Edition, California Sage, Los Angeles.

[19] Malterud, K. (2012) Systematic text condensation: A strategy for qualitative analysis. Scandinavian Journal of Public Health, 40, 795-805. doi:10.1177/1403494812465030

[20] Liebschutz, J., Savetsky, J.B., Saitz, R., Horton, N.J., Lloyd-Travaglini, C. and Samet, J.H. (2002) The relation between sexual and physical abuse and substance abuse consequences. Journal of Substance Abuse Treatment, 22, 121-128.

[21] Weber, K., Rockstroh, B., Borgelt, J., Awiszus, B., Popov, T., Hoffmann, K., Schonauer, K., Watzl. H. and Pöpster, K. (2008) Tress load during childhood affects psychopathology in psychiatric patients. BMC Psychiatry, 8, 63.

[22] Wu, N.S., Schairer, L.C., Dellor, E. and Grella, C. (2010) Childhood trauma and health outcomes in adults with comorbid substance abuse and mental health disorders. Addictive Behaviors, 35, 68-71.

[23] Schibbye, A.-L. L. (1999) The role of "recognition" in the resolution of a specific interpersonal dilemma. Jour- nal Phenomenological Psychology, 24, 175-189. doi:10.1163/156916293X00134

[24] Brousselle, A., Lamothe, L., Sylvain, C., Foro, A. and Perreault, M. (2010) Integrating services for patients with mental and substance use disorders: What matters? Health Care Management Review, 35, 212-223.

[25] Burns, T., Catty, J., Becker, T., Drake, R. E., Fioritti, A., Knapp, M., Lauber, C., Rössler, W., Tomov, T., van Busschbach, J., White, S. and Wiersma, D. (2007) The effectiveness of supported employment for people with severe mental illness: A randomised controlled trial. Lancet, 370, 1146-1152. doi:10.1016/S0140-6736(07)61516-5

[26] Bond, G.R., Drake, R.E. and Becker, D.R. (2008) An update on randomized controlled trials of evidence-based supported employment. Psychiatric Rehabilitation Journal, 31, 280-290. doi:10.2975/31.4.2008.280.290

[27] Wehman, P. (2012) Supported employment: What is it? Journal of Vocational Rehabilitation, 37, 139-142. 
[28] Cook, J. A, Razzano L.A., Burke-Miller J.K., Blyler, C.R., Leff, H.S., Mueser, K.T., Gold P.B., Goldberg, R.W., Shafer, M.S., Onken S.J., McFarlane, W.R., Donegan, K., Carey, M.A., Kaufmann, C. and Grey, D.D. (2007) Effect of co-occurring disorders on employment outcomes in a multisite randomized study of supported employment for people with severe mental illness. Journal of Rehabilitation Research \& Development, 44, 837-850. doi:10.1682/JRRD.2006.07.0079

[29] Frouenfelker, R.L., Wilkniss, S.M., Bond, G.R., Devitt, T.S. and Drake, R.E. (2011) Enrollment in supported employment services for clients with a co-occurring disorder.
Psychiatric Services, 62, 545-547. doi:10.1176/appi.ps.62.5.545

[30] Mueser, K.T., Campbell, K. and Drake, R. (2011) The effectiveness of supported employment in people with dual disorders. Journal of Dual Diagnosis, 7, 90-102. doi:10.1080/15504263.2011.568360

[31] Glover, C.M. and Frounfelker, R.L. (2011). Competencies of more and less successful employment specialists. Community Mental Health Journal. doi:10.1007/s10597-011-9471-0 